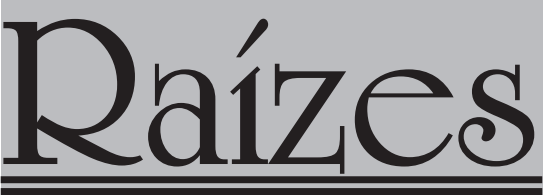

v.34, n.1, jan-jun $/ 2014$

\title{
OS “EMPODERADOS” DA AGRICULTURA FAMILIAR
}

\section{Denes Dantas Vieira}

\begin{abstract}
RESUMO
O artigo é resultado de uma pesquisa desenvolvida em dois territórios da cidadania do Rio Grande do Norte: Sertão do Apodi e Seridó, com o objetivo de analisar as trajetórias sociais e as disputas de seus agentes por diversas formas de capital, com base nos conceitos do sociólogo Pierre Bourdieu. O campo de relações da agricultura familiar nos dois territórios foi estudado de forma a identificar os conteúdos do discurso dos agentes. O termo "empoderado" foi identificado como designando aqueles que conseguiram se destacar, sendo, de fato, os grandes beneficiados pelas redes de sociabilidade e suas instituições.
\end{abstract}

Palavras-chave: Empoderamento; Habitus; Campo; Capital Social.

\section{LES “DOTÉS DE POUVOIR” DE L’AGRICULTURA FAMILIALE}

\section{RÉSUMÉ}

Cet article resulte d'une recherche développée dans deux territoires de la citoyenneté du Rio Grande do Norte: Sertão do Apodi e Seridó, dans le but d'analyser les trajectoires sociales de ses agents et leurs disputes pour diverses formes de capital, à partir des concepts du sociologue Pierre Bourdieu. Le champ de relations de l'agriculture familiale dans les deux territoires a été étudié de forme à identifier les contenus du discours des agents. Le terme "dotés de pouvoir » a été identifié comme désignant ceux qui sont arrivés à se détacher et qui sont, en fait, les grands bénéficiaires des réseaux de sociabilité et de leurs institutions.

Mots-clés: Dotés de Pouvoir; Habitus; Champ; Capital Social.

Doutor em Ciências Sociais. Professor da Universidade Federal do Vale do São Francisco. E-mail: denes.vieira@univasf.edu.br.

1 O presente artigo é parte da Tese de Doutorado defendida pelo autor em 2013, através do Programa de Pós Graduação em Ciências Sociais da Universidade Federal do Rio Grande do Norte/UFRN. 
INTRODUÇÃO

A pesquisa que resultou nesse trabalho foi desenvolvida a partir do estudo das trajetórias sociais dos agentes políticos e sociais da agricultura familiar nos territórios da cidadania do Seridó e Sertão do Apodi no Rio Grande do Norte. Para analisar as trajetórias das lideranças foram realizadas entrevistas com lideranças de organizações e projetos desenvolvidos nos municípios que compõem os dois territórios, Seridó e Sertão do Apodi.

A escolha do percurso da entrevista, locais e entrevistados, buscou identificar as lideranças que compõem o campo de relações políticas desse segmento social. As entrevistas focaram em algumas das principais lideranças nos territórios, onde foram importantes os depoimentos de agentes sindicais, religiosos, políticos com mandatos de vereadores, prefeito, educadores populares e dirigentes de Organizações Não Governamentais.

A proposta do artigo é priorizar as análises da pesquisa empírica realizada com propósito de contribuir com os estudos sobre a ação política dos grupos sociais, que compreendem a agricultura familiar enquanto categoria de ação política. O desenvolvimento das análises se restringe aos conceitos teóricos e metodológicos, habitus, campo e capital, do sociólogo francês Pierre Bourdieu.

A opção pelos conceitos operacionalizados, através da abordagem sociológica de Pierre Bourdieu ajuda na ampliação dos estudos sobre uma teoria da prática social. Os agentes pesquisados, suas trajetórias e o acúmulo de variadas formas de capital por eles usadas em um determinado campo relacional, agricultura familiar, revelam um universo analítico onde a pesquisa acadêmica tem a oportunidade de problematizar novas possibilidades de estudos para a área rural.

A análise de conteúdo das entrevistas mostrou na pesquisa uma grande riqueza na forma como os agricultores familiares e suas lideranças se organizam e se dividem nas disputas de poder e nos processos de hierarquização no interior de seu campo de relações. O artigo também colabora com o entendimento da dialética existente entre os agentes da agricultura familiar e suas instituições de base, no sentido de alargar a compreensão dos pesquisadores e dos próprios agentes envolvidos para seu papel social e político na sociedade.

\section{TEORIA E PRÁTICA SOCIAL}

O chamado campo de relações para Pierre Bourdieu é parte fundamental da explicação que sua sociologia intitula de "poder relacional". Nessa perspectiva teórica, as formas de poder residem nas relações que os indivíduos, ou agentes, acumularam ao longo de suas trajetórias sociais. Enquanto que por um lado o agente adquire poder, formas variadas de capital, em suas relações, por outro lado a matriz institucional revela características de um habitus formador.

O conceito de habitus é apresentado como um conjunto de disposições culturais, mecanismos de ação que o indivíduo adquire ao longo de sua trajetória social. Através desse conjunto de disposições flexíveis, os agentes criam estratégias, não necessariamente algo racionalizado, e assim fazem uso de variados recursos, que são usados nos campos de relações de seu espaço social. 
$\mathrm{O}$ habitus não condiciona ninguém a agir de uma forma ou de outra, ele apenas é usado como recurso pelos agentes no momento da tomada de decisão. O habitus é um "gerador de práticas sociais", sendo que o agente usa esses dispositivos culturais internalizados no processo de experiência social, para viver na sociedade, nos grupos que ele conhecerá em seu percurso presente e futuro.

Para compreender essa abordagem, Bourdieu (2011b) também propõe a noção de campo, que é desenvolvida no aspecto das estruturas que exercem coação sobre o agente. Através de uma consciência social exterior e autônoma às vontades individuais, o campo é identificado como parte da estrutura condicionadora da socialização. É através do campo que se tem a sensação de estar em um "mundo pronto", restando apenas a acomodação.

Nós vivemos em campos de relações, ou campos relacionais, logo que para Bourdieu (2011a) tudo é relacional, e a vida social é concebida através de relações entre os agentes nos espaços sociais e no interior desses mesmos campos. No nosso caso, estamos analisando um campo específico, que chamamos de campo da agricultura familiar. Para uso metodológico, falamos aqui em dois campos de relações da agricultura familiar localizados em dois espaços sociais, respectivamente referidos nos territórios do Seridó e Sertão do Apodi.

Nesse debate, cabe ao habitus, através do acúmulo de formas diferentes de capital (social, humano, econômico e simbólico) fazer com que o agente percorra os campos existentes em seu espaço social. O habitus pode, de acordo com a trajetória de cada agente, dotá-lo de poder para ser usado em um ou vários campos relacionais. A posição de cada agente no interior de um campo será definida pela quantidade de capital que ele conseguir acumular.

No debate teórico travado por Bourdieu, os agentes podem acessar alguns tipos de capital: o capital econômico, que seria identificado pela quantidade de bens materiais e recursos financeiros acumulados; o capital cultural, definido pela formação e quantidade de recursos humanos conquistados; capital social, caracterizado pela quantidade de relações estabelecidas por meio de cooperação, reciprocidade e pertencimentos mútuos adquiridos através dos processos de socialização.

Por último, Bourdieu destaca o capital simbólico, que é resultado do acúmulo por parte dos agentes de alguma das outras formas de capital já relacionadas. O capital simbólico é adquirido através do reconhecimento dos demais agentes no interior de um campo de relações no espaço social.

As categorias de habitus, campo e capital desenvolvidas a partir da teoria relacional de Pierre Bourdieu são consideradas conceitos teóricos e metodológicos. O debate conceitual apresentado aqui orienta o pesquisador nas análises e nos procedimentos de coleta de dados. Para a construção da metodologia de pesquisa é caracterizado aquilo que o artigo chama de matriz de compreensão institucional ${ }^{2}$, ou seja, um procedimento de estudo da trajetória social dos agentes da agricultura familiar nos dois territórios, Seridó e Sertão do Apodi no Rio Grande do Norte.

2 Para Bastos (2006), Instituições são estruturas sociais que regulam e dão sentido à vida das pessoas, podendo ser representadas por uma organização (institucionalizada) e/ou regras formais e informais. 
A matriz de compreensão institucional foi construída para as análises do presente artigo através da identificação das instituições prevalecentes nas trajetórias das lideranças da agricultura familiar. As instituições que mais influenciaram a formação dos agentes são consideradas prevalecentes na formação de seus habitus, seja individual ou coletivo. A pesquisa com os agentes entrevistados fez o percurso metodológico para compreender: qual e como o trabalho de organização social realizado nos dois territórios possibilitou a formação de um campo de relações políticas da agricultura familiar?

O propósito do artigo é analisar a constituição de um campo de relações políticas; nesse caso fala-se dos agentes que lideram as organizações sociais da agricultura familiar. A ideia é identificar como esses agentes acumularam diferentes formas de capital (social, cultural, humano, simbólico) ao longo de suas trajetórias, ou seja, como a formação de um habitus pode revelar as diferenças e semelhanças existentes no campo de relações da agricultura familiar.

No interior de um campo de relações, os agentes usam os tipos de capital presentes em seus habitus para exercerem poder. As regras e as normas de um campo de relações são orientadas pelos agentes melhor posicionados na hierarquia do campo, e a posição dos agentes é referendada pela qualidade e quantidade de capital que eles conseguiram acumular e que usam em suas relações.

As trajetórias dos agentes da agricultura familiar nos territórios estudados revelam uma teia de alianças, negociações e a construção de redes de socialização, que são resultados do capital social produzido pela formação de um $h a-$ bitus coletivo e também individual. Esse mes- mo capital é realimentado ao longo das atuações dessas lideranças e suas instituições no campo de relações por elas construído.

\section{SOBRE USO DAS NOÇÕES DE ESPAÇO SOCIAL, AGENTE E TERRITÓRIO}

As fronteiras de atuação do presente trabalho são circunscritas ao que se entende como território, pois o recorte da pesquisa tem como base as relações sociais das lideranças da agricultura familiar construídas nos territórios. Essa é a noção de área de atuação adotada também pelo Ministério do Desenvolvimento Agrário (MDA), através da Secretaria de Desenvolvimento Territorial (SDT), na promoção de políticas públicas.

O conceito de território ganhou densidade a partir da década de 1990, (FAVARETO, 2010). Segundo Ricardo Abramovay (2003, p. 3 ), os territórios "se constituem por laços informais, por modalidades não mercantis de interação construídas ao longo do tempo e que moldam certa personalidade e, portanto, uma das fontes da própria identidade dos indivíduos e dos grupos sociais".

Neste artigo, parte-se da ideia de território enquanto espaço socialmente organizado, onde se configura um ambiente político institucional particular à atuação de agentes sociais que, através de seus projetos de poder, constroem relações e ocupam lugares, posições em uma contínua concorrência por reconhecimento e visibilidade.

O presente trabalho faz uma analogia, uma aproximação, entre conceitos, não necessariamente iguais, entre o que Bourdieu chama de espaço social e território. Os espaços so- 
ciais são lócus privilegiados das relações entre os mais variados agentes, são como recortes de diferentes partes que se complementam e se imbricam na construção da vida social. Em Coisas Ditas, Bourdieu (2011b, p. 153) compara os espaços sociais a espaços geográficos:

É possível [...] comparar o espaço social a um espaço geográfico no interior do qual se recortam regiões. Mas esse espaço é construído de tal maneira que, quanto mais próximos estiverem os grupos ou instituições ali situados, mais propriedades eles terão em comum; quanto mais afastados, menos propriedades em comum eles terão.

Os agentes da agricultura familiar nos territórios do Seridó e do Sertão do Apodi se percebem nesses espaços e os veem como parte integrante de suas trajetórias. Os limites para a atuação desses agentes estão delimitados através de cada território, sendo por excelência a arena do protagonismo e de suas relações compartilhadas. Os espaços sociais são multirreferenciados e têm nas trajetórias de seus integrantes as respostas que explicam as propriedades em comum necessárias à estruturação de um campo específico de relações.

Outro aspecto teórico-metodológico importante - e aqui tem caráter operacional - é referente ao uso da categoria "agente". O agente em Bourdieu é concorrente, e disputa posições na hierarquia de um campo de relações. A luta por interesses move os diferentes agentes. O poder de classificar, de nomear é o objetivo perseguido no interior dos campos de relacionamento de determinado espaço social.

O agente, nessa visão, é dotado de poder e ao mesmo tempo é concorrente perante os demais agentes integrantes de um campo.
É utilizada, neste trabalho, a noção de agente para expressar o poder de liderar. Apesar de todo agente, independentemente de seu papel na hierarquia do campo, exercer algum poder, as lideranças da agricultura familiar são, aqui, compreendidas como agentes líderes.

Os agentes com atuação no Seridó e no Sertão do Apodi percebem os territórios não somente como recortes geográficos, mas como espaços de relações sociais compartilhadas, espaços de disputa, de atuação para a execução de seus projetos de poder. Nesse espaço social se inserem vários campos, entre eles o da agricultura familiar, e seus agentes se encontram para dotar o território de sentido, ou seja, este é percebido e constituído pelas práticas sociais dos que dele fazem uso.

As lideranças da agricultura familiar são agentes sociais e políticos no interior de seu campo de relaçóes e no espaço social em que atuam. Toda liderança é um agente, mas nem todo agente é, deseja ou tem a oportunidade de liderar os processos de organização social nos territórios pesquisados. Os agentes líderes são os que detêm o reconhecimento dos demais agentes no campo, possuem legitimidade para representar e falar em nome de um grupo e são respeitados por serem conhecedores das regras e normas de funcionamento do campo.

Os agentes desenvolvem algum papel de mobilização e articulação política, seja no sindicato, seja na associação, seja na Organização Não Governamental, e têm funções de liderança no campo de relações da agricultura familiar nos territórios. Constatou-se que os assessores e dirigentes de ONGs não se limitam a executar políticas públicas e mediar processos. A pesquisa constatou que as ONGs também atuam 
como representantes dos agricultores familiares e disputam com os dirigentes sindicais e de associações rurais o direito de representar o segmento, de falar em nome de uma comunidade, de um grupo. Os agentes líderes estão à frente das redes de articulação que circulam no campo. Rede e agentes são compreendidos como conceitos operacionais, metodológicos, através dos quais as relações sociais no campo e no espaço social são estruturadas.

\subsection{Os territórios do Seridó e Sertão do Apodi}

Os agentes do campo de relações da agricultura familiar nos territórios do Seridó e Sertão do Apodi costumam fazer severas críticas ao Programa Territórios da Cidadania. Há muitos questionamentos em relação à forma como a política territorial vem sendo executada, atualmente, pelo Governo Federal.

De fato, a política territorial, pelo menos no caso do Rio Grande do Norte, tem sofrido alguns reveses. Os Territórios da Cidadania, antes chamados de Territórios Rurais, estão estagnados desde meados de 2011. O Governo Federal suspendeu repasses, devido a questões relativas à prestação de contas, o que em muitos casos ocasionou a suspensão das atividades dos articuladores territoriais ou a execução das propostas deliberadas pelos Colegiados Territoriais para os municípios.

O Mapa 01 mostra o Rio Grande do Norte dividido a partir da concepção da política territorial e identifica 10 territórios potiguares: Alto Oeste, Sertão do Apodi, Açu/ Mossoró, Seridó, Sertão Central Cabugi, Mato Grande, Trairi, Potengi, Terra dos Potiguares e Agreste Litoral Sul.

\section{Mapa 1 - Mapa dos Territórios do Estado do} Rio Grande do Norte

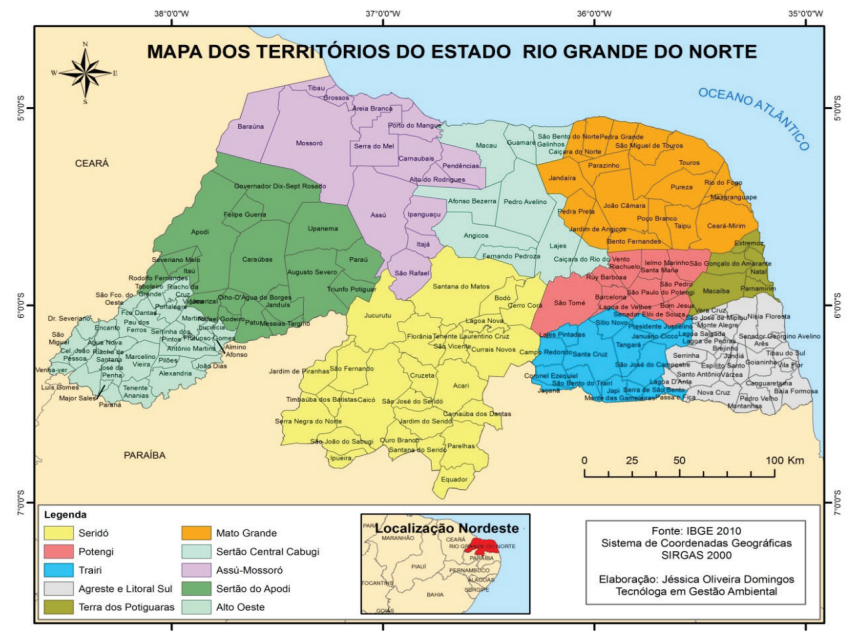

Fonte: Jessica Oliveira Domingos - Tecnologia em Gestão Ambiental.

O Sertão do Apodi tem uma área de $8.280,20 \mathrm{Km}^{2}$ e representa os municípios de Apodi, Caraúbas, Felipe Guerra, Itaú, Janduís, Messias Targino, Olho d'Água do Borges, Paraú, Patu, Rafael Godeiro, Rodolfo Fernandes, Severiano Melo, Triunfo Potiguar, Umarizal, Upanema, Augusto Severo e Governador DixSept Rosado.

A população total do território é de 157.247 habitantes, dos quais 55.790 vivem na área rural, o que corresponde a $35,48 \%$ do total. O território possui 9.152 agricultores familiares e 2.860 famílias vivendo em áreas de assentamento rural destinadas à reforma agrária, contando também com uma comunidade quilombola.

O Seridó possui uma área de 10.954,50 $\mathrm{Km}^{2}$ de extensão e abrange 25 (vinte e cinco) municípios, quais sejam: Acari, Bodó, Caicó, Carnaúba dos Dantas, Cerro Corá, Cruze- 
ta, Currais Novos, Equador, Florânia, Ipueira, Jardim de Piranhas, Jardim do Seridó, Jucurutu, Lagoa Nova, Ouro Branco, Parelhas, Santana do Matos, Santana do Seridó, São Fernando, São João do Sabugi, São José do Seridó, São Vicente, Serra Negra do Norte, Tenente Laurentino Cruz e Timbaúba dos Batistas.

É a partir da ideia de território que os agentes se referem aos espaços sociais nos quais atuam. Um ambiente institucional foi sendo forjado para dar legitimidade a ações, programas e projetos de um variado grupo de agentes nesses territórios.

No caso do Seridó, o território já é “o território", no sentido de que antes da política territorial, o Seridó já era Seridó e assim identificado e concebido por seus agentes. No caso do Sertão do Apodi, essa concepção existia de forma frágil e isolada, foram a política territorial e seus desdobramentos que na década de 2000 produziram sua legitimidade. Se perguntar para a população desse território qual é o significado do Sertão do Apodi, certamente não se identificará reconhecimento para essa concepção de espaço.

\section{SOBRE AS TRAJETÓRIAS DOS AGENTES}

A pesquisa que resultou no presente artigo buscou identificar e compreender o lugar do capital social nos territórios, considerado o principal produto e reprodutor das relações sociais em questão, e como o capital social, enquanto recurso de poder, foi utilizado pelas disposições culturais que cada agente tem para agir com base no habitus adquirido, na formação de um campo de relações. A luta simbólica entre os agentes nos territórios emerge das re- lações que eles processam no campo de poder da agricultura familiar.

A identificação de matriz de compreensão institucional dos agentes da agricultura familiar nos territórios pesquisados é alicerçada na atuação da tríade Igreja, Sindicato e Partido Político, tanto no Sertão do Apodi quanto no Seridó. A presença da instituição Igreja é crucial para os processos analisados no presente trabalho.

Enquanto no Sertão do Apodi a Igreja foi instrumentalizada pelos agentes em torno de seus projetos, ou seja, serviu como base e ferramenta do processo de empoderamento para a luta no campo de relações constituído no território, no Seridó, a Igreja e seus tentáculos de atuação ainda persistem. No Seridó, a Igreja mesmo sem a mesma força de antes, se não pela força política mas pela força da tradição, tem enorme poder coercitivo sobre suas "crias", ou seja, sobre os agentes dos quais ela continua pensando ser responsável.

\subsection{No SERIDÓ}

No Seridó, identificou-se um espaço social erguido sob a forte influência da religiosidade da Igreja Católica. Falar do Seridó é se perguntar como uma instituição religiosa conseguiu de forma tão contundente contribuir com a estruturação da vida social de toda uma população. O discurso do seridoense é regido pela necessidade de compartilhar um território, de produzir e inventar símbolos e significados comuns. Assim, dizer-se seridoense é antes de tudo uma estratégia de sobrevivência e ocupação de um lugar no mundo. 
Não diferente dos demais campos que estruturam o território do Seridó, o campo de relações da agricultura familiar recebeu forte influência da Igreja Católica. A instituição Igreja, com seus órgãos de atuação e o poder de uma religiosidade, teve como principal função no campo da agricultura familiar produzir laços de identidade compartilhados entre os seus agentes.

A Igreja Católica foi fundamental para criar um ambiente favorável ao surgimento de lideranças da agricultura familiar. Esses agentes líderes são oriundos das comunidades rurais assistidas pela Igreja, através de suas ações de formação política e social no território. Foi constatada pela pesquisa a presença de uma Igreja bastante ativa, a partir da década de 1950, atuando de maneira a criar e organizar os primeiros sindicatos de trabalhadores rurais do território.

A sindicalização dos agricultores era incentivada como forma de garantir a influência da Igreja sobre o território. Em grande parte isso era explicado pelo receio com o avanço das Ligas Camponesas, que na década de 1950 se aproximavam do Seridó pelo Estado vizinho da Paraíba A Igreja Católica tornou-se assim a instituição central de uma matriz que estruturou a trajetória social dos agentes do território.

Através da centralidade da instituição Igreja e de todo o legado cultural cultivado pelo Seridó, o sindicalismo rural do território adquiriu traços políticos que remetem a uma insistente tradição que seus agentes propagam. $\mathrm{O}$ sindicalismo rural do Seridó influenciou a trajetória de seus agentes na perspectiva de formar lideranças tradicionais, com uma atuação muito voltada para as relações produzidas, quase sempre, no âmbito do próprio território ou de seus municípios.

O Seridó, por si só, é uma rede de articulação política, um espaço de poder construído e defendido por seus agentes. Tem-se a impressão de que eles se relacionam com os demais espaços de articulação fora dos limites do Seridó, por ser inevitável, uma vez que, se pudessem, evitariam. O Seridó se basta para os Seridoenses.

O campo da agricultura familiar do Seridó é homogeneizado pelo poder seridoense, tratando-se de um recurso simbólico usado, como já dito, também para intimidar seus concorrentes e produzir visibilidade no espaço social circunscrito do próprio território e do espaço social ampliado de atuação no Rio Grande do Norte.

A construção desse campo teve a contribuição da força da Diocese de Caicó, onde, a partir da década de 1950, as paróquias serviram de apoio para a criação de sindicatos. Já nas décadas de 1980 e 1990, o desempenho da Igreja ficou sob a responsabilidade de seus órgãos e serviços de atuação para a questão social, tendo papel importante na organização das relações de um campo político para os agentes da agricultura familiar.

Por muito tempo, a Igreja Católica do Seridó priorizou a criação de associações rurais e a formação de novas lideranças no território. Já em meados dos anos de 1990 e início do novo século, a harmonia desse campo foi quebrada com o estabelecimento da rivalidade dos antigos parceiros. De um lado, a Igreja, e do outro, a sua criatura, os sindicatos da Federação dos Trabalhadores na Agricultura do Rio Grande do Norte/FETARN. Em disputa figurava a 
rede de associações, que em parte foi criada e incentivada pela atuação da Igreja no território, mas que sem a legitimação dada pelos sindicalistas, possivelmente, não teria ocorrido.

A concorrência pelo "poder de nomear", de oferecer sentido, falar em nome desse campo de relações em disputa tornou-se conflituosa em demasia para os mais tradicionais agentes da agricultura familiar do Seridó. Os agentes, não mais satisfeitos com suas conquistas até então, intensificaram a luta por novas posições no espaço social ampliado do território, o que ocorreu devido às ambições produzidas pelas disposições de seu habitus em atuar no campo da política partidária.

A partir de então, é celebrada uma parceria, formada por grupos aliados em torno da política partidária, movimentos sociais e algumas das principais redes de articulação, envolvendo ONGs, sindicatos, associações etc. Disso, resultou a construção de uma grande estrutura de reprodução do poder desses grupos, proporcionada, também, pela execução do Programa de Combate à Pobreza Rural (PCPR), que na década de 2000 foi intitulado, no Rio Grande do Norte, de Programa Desenvolvimento Solidário (PDS).

As ações do PCPR montaram uma máquina associativista que ofereceu grande visibilidade política aos seus representantes nos territórios e os agentes do Seridó foram os que mais conseguiram tirar proveito desse momento. No entanto, faltou unidade de ação entre aqueles que sempre se utilizaram do discurso da identidade coletiva. Diante da falta de um projeto comum em torno de nomes para liderar esse campo de relações no Seridó, qualquer tentativa maior de mobilidade de seus agentes no espaço social ampliado do território resultou em enormes fracassos.

As experiências bem-sucedidas do Seridó no que se refere à conquista de mandatos eletivos e maior participação no cenário político do território são limitadas, quase sempre, aos pequenos municípios. É o caso de Florânia, Cerro Corá, Lagoa Nova, São João do Sabugi e Serra Negra do Norte, cujas experiências se limitam a ambientes institucionais muito circunscritos e marcados, no caso dos dois primeiros, pela mão de ferro de suas lideranças, a partir da formação de verdadeiras oligarquias sindicais.

O habitus dos agentes do Seridó tem origem em uma matriz marcada pela trajetória social, fortemente alicerçada em instituições que influenciaram suas disposições para agir no campo de poder constituído para o debate da agricultura familiar. Como já frisamos, o papel desempenhado pela Igreja, sem dúvida alguma, possui grande centralidade; no caso do Seridó, trata-se de uma instituição que não admite ser coadjuvante. Ela mesma é o maior e mais importante agente desse campo no território, do qual nunca saiu de cena.

A matriz de compreensão institucional do habitus dos agentes do Seridó diz muito sobre a forma como seus agentes se comportam. No Seridó, a presente pesquisa identificou uma forte reprodução das estruturas coercitivas do campo de relações da agricultura familiar sobre os agentes e uma margem muito estreita do habitus em produzir algo diferente do que as instituições daquele espaço social, ao longo de suas trajetórias, neles internalizaram.

Ou seja, o tal sentimento de identidade seridoense, capital simbólico acumulado que 
consequentemente está no habitus dos agentes do campo da agricultura familiar, foi forjado pela atuação de instituições que ao longo do tempo usam esses agentes em suas disputas por poder e capital para, assim, conservarem viva a representação de um espaço social diferenciado.

O capital simbólico dos seridoenses no campo da agricultura familiar e no espaço social do território é produto e reprodutor de suas instituições. O capital social do Seridó é facilmente confundido com o que muitos chamam de "bairrismo", expressão que serve para designar a defesa fervorosa dos valores e qualidades de um lugar, território, espaço social, em detrimento de outros.

Como já analisado, apesar de os recursos construídos e mobilizados pelos agentes do Seridó estarem disponíveis para uso em todo o espaço social do território, apenas alguns conseguem fazer uso disso. A distribuição de poder e a manipulação dos diferentes recursos por partes dos agentes no campo de relações da agricultura familiar são realizadas de forma desigual. Os valores seridoenses resultam em ganhos e conquistas para aqueles que estão mais engajados nas redes de articulação do território.

\subsection{No SERTÃo do Apodi}

Já no território do Sertão do Apodi, há uma heterogeneidade maior no que se refere a valores supostamente compartilhados pelos agentes da agricultura familiar. Nesse território, a configuração espacial não obedece, nem de longe, aos mesmos atributos de pertencimento mobilizados pelos seus vizinhos seridoenses. O Seridó já era Seridó antes da políti- ca territorial ou de qualquer demanda política externa, ao contrário do Sertão do Apodi, que, em outras perspectivas, também é chamado de Oeste Potiguar ou Médio Oeste.

A composição dos agentes do campo de relações da agricultura familiar constituído no Sertão do Apodi segue a pluralidade e a diversidade social identificadas em seu espaço social. A Igreja Católica também desempenhou, nesse território, função preponderante na formação de um habitus para seus agentes, mas não possui a mesma importância para a estruturação da matriz de compreensão institucional desse mesmo habitus, como analisado no caso do Seridó.

A Igreja Católica atuou fortemente para organizar e dotar de um senso crítico inúmeros jovens que hoje são agentes políticos da agricultura familiar no campo de relações erguido naquele espaço social. A grande característica da influência da Igreja no primeiro momento da constituição de um campo de poder no Sertão do Apodi, iniciado ainda na década de 1960, foi marcada pela formação política e social oferecida a grupos de jovens e associações rurais. Posteriormente, muitos desses jovens se tornaram lideranças que renovaram o movimento sindical rural, criando novas associações, cooperativas e Organizações Não Governamentais, que, atualmente, protagonizam a cena política do segmento no território.

Porém, no Sertão do Apodi, a Igreja não possui a mesma centralidade e influência sobre a matriz do habitus dos agentes, como ocorre no caso do território do Seridó. Foram os sindicatos e os partidos políticos que produziram disposições para as práticas sociais dos agentes, em alguns casos até mais representativas do que a Igreja Católica conseguiu. 
A Igreja saiu de cena no Sertão do Apodi e deixou que o protagonismo fosse exercido pelos jovens por ela formados. Nesse território, a atuação dos agentes em sindicatos e nos partidos políticos foi potencializada pela chegada/ou criação de ONGs. As ONGs são compreendidas como instrumentos de reprodução dos projetos de poder dos agentes, que agem a partir das disposições da matriz do habitus e não como parte desta. As instituições que compõem mais fortemente esse habitus, ao longo do tempo, instrumentalizaram as ONGs para a reprodução de seus recursos e valores.

A reconhecida organização social do Sertão do Apodi é resultado da intervenção de instituições que, ao longo dos últimos 30 anos, produziram e mobilizaram em seu território importantes laços de cooperação e participação entre os agentes, que, atualmente, integram o campo de poder da agricultura familiar. A presença de uma Igreja com visão social progressista, aliada a sindicatos fortes e concentração de ONGs atuando na organização social, é característica dos processos sociais que se desenvolvem no Sertão do Apodi.

É muito instigante estudar a ação política dos agentes da agricultura familiar no Sertão do Apodi. Nesse território, a matriz institucional que deu origem ao habitus dos agentes da agricultura familiar produziu um dos mais visíveis e consolidados campos de relações para esse segmento.

3.3 A FORÇA DO HABITUS NA FORMAÇÃO DOS EMPODERADOS

Os agentes da agricultura familiar do Seridó, em seus discursos, exaltam suas quali- dades políticas como uma disposição intrínseca da sua história. Contudo, Bourdieu (2011a) também diz que o habitus age sobre o agente "quase que no corpo", ou seja, talvez faça sentido os seridoenses se sentirem com um "DNA" diferenciado, pois é isso mesmo que o habitus produz nos agentes, ou seja, suas disposições culturais estão tão incorporadas, inclusive na sua postura, que se tem a sensação de que algo que é essencialmente social possa ser biológico.

Já os integrantes desse campo no Sertão do Apodi falam sobre uma construção difícil e contínua de iniciativas de organização social e aprendizagem política, muitas vezes conflituosa. As matrizes Igreja, sindicato e partido político desempenharam papéis diferentes na formação do habitus dos agentes e nos desdobramentos de suas ações nos campos dos dois territórios.

As análises da pesquisa que resultaram no presente artigo afirmam que os campos de relações da agricultura familiar nos territórios do Seridó e Sertão do Apodi são bastante diferentes no que se refere ao papel desempenhado pelo habitus dos seus agentes. Apesar da mesma matriz de compreensão institucional, fundada no tripé Igreja, sindicato e partido político, o habitus dos agentes estudados sofreu influências quase antagônicas dessas instituições em suas trajetórias.

Esse aspecto, como já dito, tem relação com a forma como as instituições da matriz, em menor ou maior medida, interferiram no conteúdo do habitus dos agentes e nas suas práticas sociais no interior do campo de relações da agricultura familiar. As instituições nos dois territórios pesquisados possuem singularidades, o que foi fundamental para a produção de resultados diferentes, remetendo a conclusões 
sobre a maneira como os agentes estruturam o campo de relações e suas estratégias de acumulação das formas de capital disponíveis em cada território.

As posições dos agentes pesquisados nos seus respectivos campos de atuação representam o modo como eles conseguiram acumular capital social e revertê-lo em outros recursos para serem usados nas disputas e concorrências por reconhecimento e legitimidade em seus territórios.

Enquanto no campo de relações da agricultura familiar no Seridó o habitus dos agentes os orientou para uma prática social pouco diversificada, no Sertão do Apodi observou-se a existência de uma dinâmica social mais plural e multirreferenciada. O habitus dos agentes seridoenses atuou na produção de ações muito mais voltadas para as questões do próprio território, aliadas a uma frágil variedade de agentes, o que se traduz no que os próprios seridoenses chamam de "cultura diferenciada".

\section{CONSIDERAÇÕES FINAIS}

O maior resultado da pesquisa realizada não é apenas realçar as diferenças existentes no modo como um habitus comum à atuação dos agentes da agricultura familiar em dois espaços sociais diferentes, aqui também chamados de territórios, conseguiu construir e mobilizar distintas formas de capital social. Até porque, conclui-se que o capital social foi, nessas situações estudadas, um recurso apenas inicial desses agentes para a obtenção de outras formas de capital, objetivando com isso o controle do campo, sua hegemonia, através do exercício da violência simbólica, ou seja, buscando tornar suas ideias as ideias do campo.
Os territórios do Seridó e do Sertão do Apodi são espaços sociais que, através de instituições prevalecentes, ou seja, de uma matriz de compreensão comum ao habitus de seus agentes, conseguiram produzir dois campos de poder, onde, de forma desigual e hierarquizada, grupos sociais circunscritos a determinados agentes líderes levam adiante seus projetos de poder.

O trabalho também compreende que os ganhos distribuídos de maneira não horizontalizada, recursos esses mobilizados pelos agentes, não têm nada de ilegítimo, apenas fazem parte do jogo de poder no campo em que atuam. $\mathrm{O}$ papel do cientista social é problematizar essa realidade e ressaltar como e de que forma isso ocorre em um processo social. O que acontece nos territórios do Seridó e do Sertão do Apodi não revela apenas diferenças de capital social, mas, fundamentalmente, mostra que os resultados das disputas nesse campo são por poder e, consequentemente, pelo controle das melhores posições.

Argumenta-se que o capital social não necessariamente é um bem coletivo, no sentido de seu uso ampliado. Os agentes da agricultura familiar, tanto no Seridó quanto no Sertão do Apodi, têm no capital social seu poder para agir e acessar outras formas de capital, mas esse mesmo recurso acabou por dar forma e conteúdo a uma comunidade fechada de agentes que se beneficiam de seus ganhos.

Esse capital social analisado tem pouca relação com o propagado na literatura mais recorrente, como vimos na Introdução: uma perspectiva trabalhada como capital social sinônimo sempre de um bem coletivo e promotor da equidade social. O capital social analisado aqui difere, pois constata que os recursos es- 
tão em disputa e que há uma concorrência dos agentes pelas melhores posições no interior de um campo de relações.

O habitus dos agentes é decisivo para a posse das formas de capital disponíveis no campo. No caso dos agentes estudados, o capital social tem melhor uso por parte dos que conseguiram ao longo de suas trajetórias acumulá-lo e usá-lo no campo. Os agentes da comunidade fechada de capital social são os empoderados, ou seja, aqueles que de fato são os grandes beneficiados pelas redes de sociabilidades e suas instituições no campo.

A adoção do termo "empoderado" não é alusão a nenhuma teoria do empoderamento ou empowerment. A análise das trajetórias sociais dos agentes identificou o termo empoderamento em seus discursos como forma de fazer referência àqueles que, pelas ações desenvolvidas, conseguiram se destacar. Então, tratase de uma apropriação discursiva do termo empoderamento.

Nesse sentido, quando os agentes entrevistados estão falando dos que passaram por algum processo social de organização, capacitação e experiências com ações coletivas promovidas por Igrejas, sindicatos, ONGs, associações, cooperativas, partidos políticos, governos etc., enfim, indivíduos e grupos que se destacaram no campo de relações da agricultura familiar, ocupando posições de poder, na verdade, estão refletindo sobre eles mesmos.

Os empoderados hoje estão a coordenar, assessorar e desenvolver atividades nas ONGs dos territórios, dirigindo os sindicatos e presidindo muitas associações, cooperativas e grupos que atuam diretamente com os agricultores em suas comunidades e áreas de assentamentos ru- rais. Na busca pela ampliação de suas capacidades de ação e mobilidade entre um campo e outro no mesmo espaço social, eles também ocupam ou ocuparam cargos nos governos e mandatos de vereadores, vice-prefeitos, prefeitos.

As oligarquias sindicais, em que esposa, filhos e filiados do grupo do presidente se consolidaram em décadas de gestão, como identificado na pesquisa, também são expressões dessa comunidade fechada de capital social. Os eternos presidentes de associações e sindicatos são caricaturas desse empoderamento da comunidade fechada, assim como os dirigentes de ONGs que, além de executarem os projetos planejados para uma determinada área, também querem executar seus projetos político-partidários.

O acesso à informação, através da participação contínua nas ações desse campo, produz inúmeras facilidades para determinados agentes. É o capital social em ação, afinal é para isso que ele serve, para facilitar a vida das pessoas. Nessa perspectiva, precisa incluir na lista dos exemplos de comunidade fechada aquelas áreas, comunidades dos territórios onde as lideranças foram alvo dos primeiros investimentos de projetos de geração de renda, construção de cisternas, irrigação, crédito desburocratizado, etc.

Por fim, a presente pesquisa finaliza sua contribuição para a problematização relativa ao campo acadêmico da agricultura familiar. É defendida a ideia de que os processos sociais nas áreas rurais precisam ser analisados com enfoques teóricos que não enfatizem, necessariamente, as estratégias de resistência, como é comum nesse variado segmento social, aqui representado pelos agentes de um campo. Mas é 
preciso que as pesquisas apontem para o alargamento da compreensão de suas práticas sociais, de como se posicionam e lidam com o poder inerente às relações concebidas e processadas em suas relações.

O esforço para compreender os empoderados da agricultura familiar e suas comunidades fechadas de capital social quis contribuir para entender como práticas sociais produzidas em campos de diferentes espaços sociais, Seridó e Sertão do Apodi, reproduziram formas diferentes de poder, mas que resultaram no mesmo propósito, ou seja, em hierarquização e desigualdade em seu acesso.

Trabalho recebido em 10/02/2014 Aprovado para publicação em 20/05/2014

\section{REFERÊNCIAS BIBLIOGRÁFICAS}

ABRAMOVAY, Ricardo. O futuro das regiões rurais. Porto Alegre: Editora da UFRGS, 2003.

ABU-EL-HAJ, Jawdat. O debate em torno do capital social: uma revisão crítica. Revista brasileira de Informação bibliográfica em Ciências Sociais, Rio de Janeiro, 1999.

BASTOS, Fernando. Ambiente institucional no financiamento da agricultura familiar. São Paulo: Polis, 2006. v. 600, 255 p.

BAQUERO, Marcelo (Org.). Raízes do Capital Social. In: . Reiventando a sociedade na América Latina: Cultura Política, Gênero, Exclusão e Capital Social. Porto Alegre: Editora da UFRGS, 2001.
BOURDIEU, Pierre. A distinção: crítica social do julgamento. São Paulo: Edusp; Porto Alegre: Zouk, 2007.

O Poder Simbólico. 15. ed. Rio de Janeiro: Bertrand Brasil, 2011a. se, $2011 b$. Coisas Ditas. São Paulo: Brasilien-

O Capital Social: notas provisórias. In: NOGUEIRA, Maria Alice; CATANI, Afrânio (Org.). Escritos de educação. Petrópolis: Vozes, 1998. p. 67-69

CRUZ, Dalcy da Silva. O sindicalismo rural e a luta pela terra. 1992. Dissertação (Mestrado em Ciências Sociais) - Programa de Pós Graduação em Ciências Sociais, Universidade Federal do Rio Grande do Norte, Natal, 1992.

DUQUE, Ghislaine. A Articulação do Semiárido: camponeses unidos em rede para defender a convivência no semiárido. In: FERNANDES, Bernardo Mançano; MEDEIROS, Leonilde Servolo; PAULILO, Maria Ignez (Org.). Lutas camponesas contemporâneas: condições, dilemas e conquistas. São Paulo: Editora da UNESP, 2008.

FAVARETO, Arilson da Silva. As politicas de desenvolvimento territorial rural no Brasil em perspectiva: uma década de experimentações. São Paulo: Desenvolvimento em Debate (INCT/PPED), 2010. v. 1, p. 47-63.

PAIVA, Irene Alves. A Igreja e a Construção de um Espaço Público. In: ANDRADE, Ilza Araújo Leão (Org.). Igreja e Política no Rio Grande 
do Norte: momentos de uma trajetória. Natal: Sebo Vermelho, 2000. p. 178-199.

PUTNAM, Robert D. Comunidade e democracia: a experiência da Itália moderna. Rio de Janeiro: FGV, 1996.

SADER, Eder. Quando novos personagens entram em cena: experiências e lutas dos trabalhadores da grande São Paulo (1970-1980). 4. ed. São Paulo: Paz e Terra, 2001. 